\title{
Terrain Analysis of Biu Plateau, for Road Transport Development, Borno State, Nigeria
}

\author{
Ikusemoran Mayomi ${ }^{1}$, John Abdullahi ${ }^{1} \&$ Anthony Dami ${ }^{1}$ \\ ${ }^{1}$ Department of Geography, University of Maiduguri, Maiduguri, Nigeria \\ Correspondence: John Abdullahi, Department of Geography, University of Maiduguri, Maiduguri, Nigeria. \\ E-mail: johnabdullahi@ymail.com
}

Received: August 5, 2013

Accepted: August 25, 2013 Online Published: April 1, 2014

doi:10.5539/jgg.v6n2p28

URL: http://dx.doi.org/10.5539/jgg.v6n2p28

\begin{abstract}
Among all the means of transportation, road has been described as the most important, probably because of its flexibility and its low cost in terms of construction, maintenance and usage. However, in Nigeria, road is considered to be the most dangerous means of transportation because of their bad nature such as sharp bends, narrow bridges, steep slopes and other related problems which are associated with the terrain where these roads are constructed. Road transportation therefore needs proper planning and development through the use of geo-information technologies that would ease accessibility reduces human energy and yet brings reliable and accurate information on the terrain. In this paper, Ilwis 3.5 was used to create Digital Elevation Modelling (DEM), Shadowing, 3-Dimentional View, Slope maps and river direction maps of Biu plateau to analyze the use of GIS on road planning and development on the plateau. It was revealed that the technique has great capabilities of terrain analysis as features which are deemed humanly impossible to assess are viewed as if one is at the scene which may enhance quick analysis on road transportation. It was therefore, recommended that all the stake holders in road transportation should employ the use of this geo-information techniques in terrain analysis to ease transport planning and development in the area.
\end{abstract}

Keywords: GIS, terrain, DEM, road, transportation

\section{Introduction}

Road transportation is the most popular transportation system in Nigeria which forms the bedrock of the exchange economy of the country. According to Oboli (1981) construction of roads in Nigeria started in 1906 and since then, road network has developed so widely. In 1950, for instance, there were some 45,000 kms of road of which only 1650 were bituminous-surfaced. By 1960 , the total had risen to some $72,000 \mathrm{kms}$ of which $8700 \mathrm{kms}$ were bituminous surfaced. In 1975, about 90,000 kms of which well over 15,000 kms were asphalted (Oboli, 1981). Today, there are so many kilometres of road network in most places in Nigeria.

According to Mohammed and Muhammad (2009), the Federal Government has been allocating funds for the construction, rehabilitation and expansion of roads as reflected in the various government developmental plans such as rolling plans for the $1^{\text {st }}, 2^{\text {nd }}, 3^{\text {rd }}$ and $4^{\text {th }}$ period supplemented by other supporting programmes like the Integrated Rural Development (IRD), National Road Development Fund (NRDF), Directorate of Food, Road and Rural Infrastructure (DFFRI) and Petroleum (Special) Trust Fund (PTF). One of the major problems that confronted all these developmental programmes is the influence of the physical environment such as rugged topography, sandy nature of the soil, presence of large rivers as well as thickly forested and swampy nature of some areas. Therefore, in this modern day of technology, there should be a means of assessing the terrain of an area for the purpose of road development and maintenance, where the topography, the slope, the locations of rivers, the land-use and land-cover can easily be analysed.

The advent of digital technology has enabled the representation of the terrain of the land surface in Digital Elevation Models (DEMs) which are numerical representation of both planimetric detail and height information (Wali \& Dabo, 2009). DEMs are produced by the use of Geographical Information System (GIS) techniques. GIS is a computer system that records, stores, and analyzes information about the features that make up the earth's surface. The computer based GIS can provide automated assistance to road developmental terrain analysis functions such as computing slopes and visibility (Ndukwe, 2001), while the civil engineers can use the models for design and execution of projects such as cross sectioning, profile drawing, road alignment, earth work (cut 
and fill) computation (Wali \& Dabo, 2009).

\subsection{Statement of the Problems}

Biu plateau has been known from various literatures (Iloeje, 2007; Oboli, 1981; Udo, 1982) to be characterised by numerous plateaus with extinct volcanic cones cut with a number of small rivers. No doubt, construction of roads on this type of terrain where the slopes are steep and the valleys are deep with the use of manual terrain analysis will be difficult leading to low quality of roads because of scarp nature, sharp curves and unnecessary crossing of numerous rivers which may increase road accidents. GIS is therefore, the only technology which can integrate all the physical and cultural features for terrain analysis. Linda (2003) observed that GIS has the capability to receive, reformat, create, store, retrieve, update, manipulate and condense digital terrain data to produce terrain analysis products such as: modified combined obstacle overlays, hydrology overlays, slope maps, on and off road mobility maps, line-of -sight plots, concealment maps and possible problems associated lines of communication.

\subsection{The Study Area}

According to Udo (1982) Biu Plateau is a plateau in North-Eastern Nigeria, located between latitudes 10'30"N and10'45"N and longitudes 12'00"E and 12'15"E (Federal Survey, 1968). The Biu plateau is a structural and topographic divide between the Upper Benue to the south and the Chad Basin to the north. The plateau is a rugged terrain overlain by volcanic rocks with an extent of over $500 \mathrm{kms}$. A number of well preserved hills made up of basaltic agglomerates, ash, lavas and tuff create miniature escarpment and also form permanent relief features in the northern parts of the plateau. The elevation of the plateau descends gradually to the north and to the west, while the highlands of the plateau pass into the plains underlain by basaltic rock north of Buratai and east of Miringa. The Miringa volcanic zone has a number of well preserved volcanic cones, which stands above the plateau, along north-northwest to south-southeast axis. These cones are characterized by well defined craters with breached rims and steep conical sides.

Maiduguri Metrological Services (1992) described Biu plateau as an area that is characterized by three seasons: the cold dry season (harmattan) from October to March, hot dry season from April to June and rainy season from July to September. Temperatures are high all the year round with hot season temperature ranging between 39 and $47^{\circ} \mathrm{C}$. The mean annual rainfall on the plateau is about $800 \mathrm{~mm}$ and rain season lasts for about 150 days. The plateau is covered with the Sudan savannah type of vegetation which consists mainly of scrub vegetation interspersed with tall trees and woodland. The vegetation has been greatly modified in most parts of the area as a result of over cultivation and overgrazing.

The scope of the study extends from latitudes $10^{\circ} 33^{\prime} \mathrm{N}$ to $10^{\circ} 40^{\prime} \mathrm{N}$ and longitudes $12^{\circ} 09^{\prime} \mathrm{E}$ to $12^{\circ} 14^{\prime} 30^{\prime \prime} \mathrm{E}$. This area is "sub-mapped" because it contains almost all the landforms that are found in the entire Biu region such as plateau, valleys, rivers and also roads.

\section{Materials and Methods}

\subsection{Description of Materials}

The Software packages used are of two categories: the GIS and non-GIS packages respectively. The GIS Software package was ILWIS 3.2 Academics for geo-referencing, digitizing, contour interpolation (DEM); filter and application of DFDX 3D. Other non-GIS Software packages include Corel 12 for map scanning and export of the map to ILWIS.

\subsection{Sources of Data}

Topographical map of Biu Sheet 133 SW which was compiled and drawn by the Federal Surveys, Nigeria, 1968 from photo-reduction of 1:50,000 were acquired from the Ministry of Land and Survey, Maiduguri for this study.

\subsection{Data Preparation for Spatial Analysis}

The acquired topographical map was scanned from the CorelDraw environment and exported as Tagged Image File-TIFF file type. The processes of geo-referencing were carried out in the ILWIS environment so that the pixel of the maps can conform to the actual coordinates of the points they represent on the ground. The contour of the topographical map representing the relief was digitized and interpolated in ILWIS environment to create a Digital Elevation Models (DEM) of the plateau. The DEM was also used to generate shadow and slope maps in degrees of the plateau. The existing road network, existing drainage system, and the settlements were also digitized and overlain on the DEM/slope maps which served as spatial data layers for the spatial operations. Finally 3D views and shadow maps were created of the DEM through the Display 3D module of ILWIS software so as to have a clearer view of the DEM. 


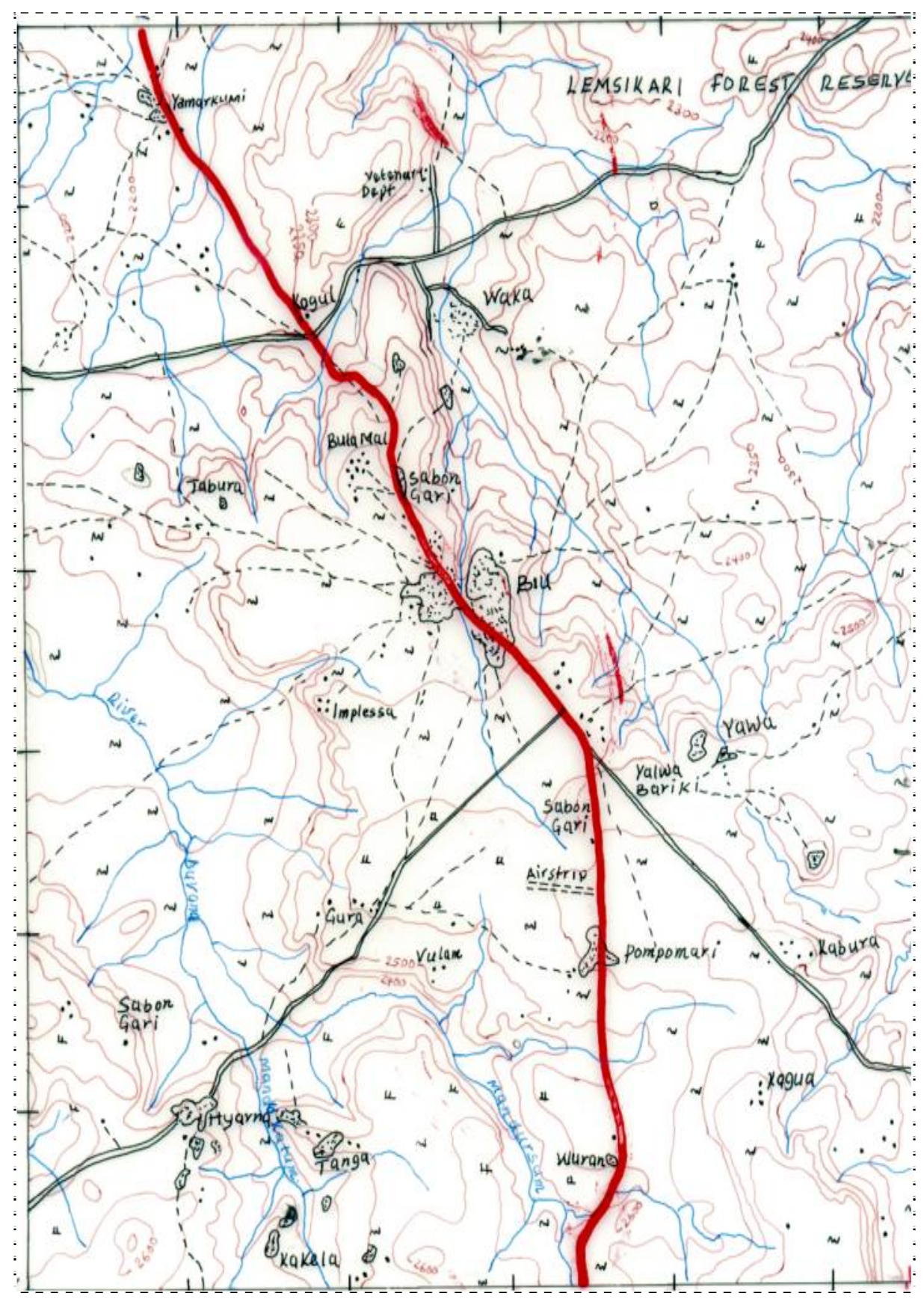

Figure 1. The study area

\section{Data Presentation and Discussion of Results}

Figure 2 shows the DEM of the Biu plateau. The essence of DEM is to view the topography of an area without necessarily visiting or having pre-knowledge or idea about the topography of the area. In DEM map, colours are used to delineate the different height values of an area. In this paper, the Biu DEM revealed that the height of the region ranges from $2131.5 \mathrm{ft}$ (minimum height represented with blue colour) to $2644.7 \mathrm{ft}$ maximum height shown with pink colour). The heights are shown in feet because the contour lines on the base topographical were in feet. The DEM map revealed that though there are more settlements on the plateau than the plain areas, but road networks are more in the plains than the top of the plateau. For instance, on the plains (blue and green colour areas) there was the main road that runs from the north through Yamishika and Biu to the south. There were also secondary roads running from east to west in the area as well as numerous footpaths. The airstrip was also discovered to be sited on the relatively flat part (pink colour) on the top of the plateau. Some villages such as Kagua, Kakala, Tanga and Vulam which are all located on the plateau tops are not even connected with any 
means of transportation probably because of the deep valleys of the area. Finally it was also revealed that the roads were constructed at places where river crossing is minimal which might reduce the cost of the construction of such roads since only few bridges would be constructed.
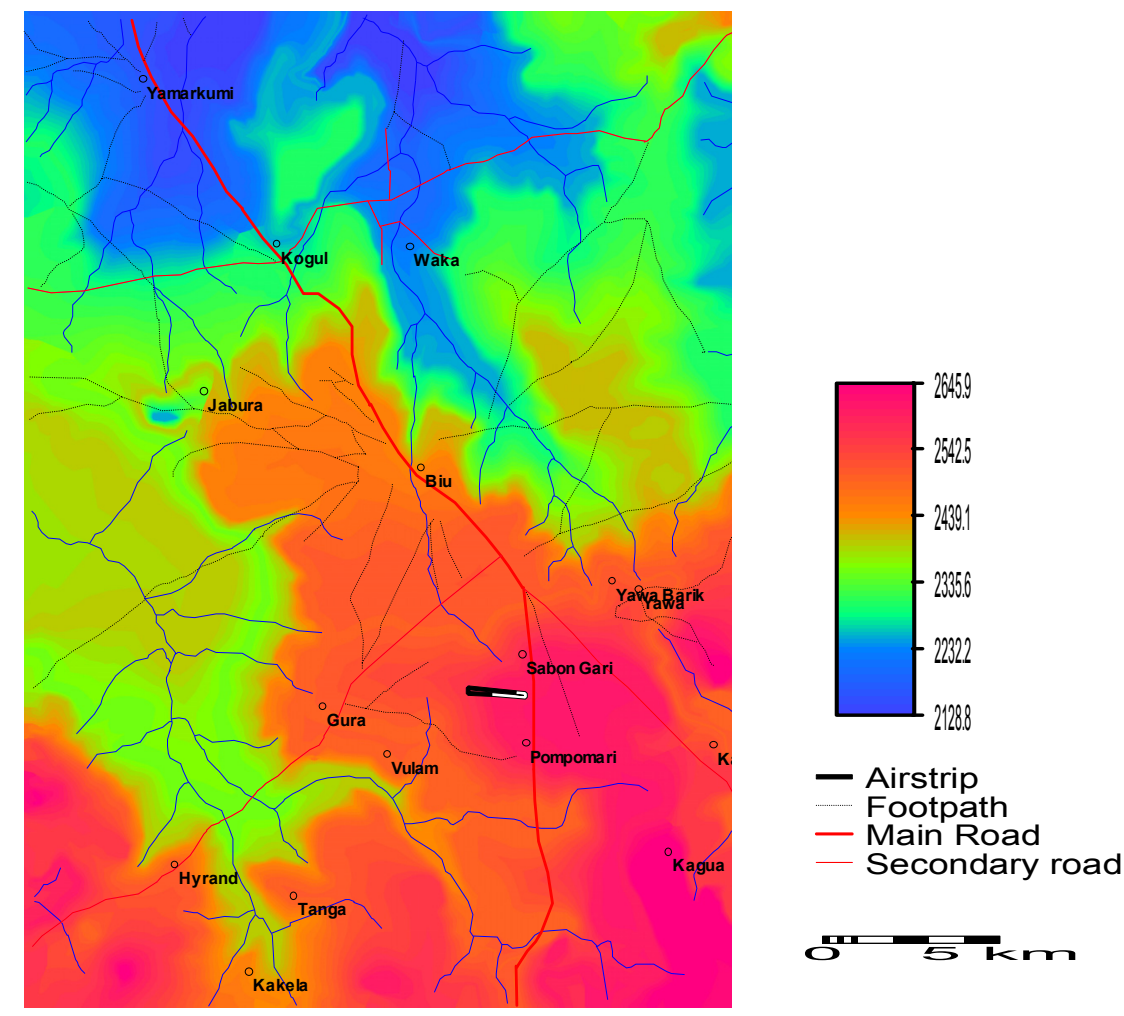

Figure 2. The DEM of the study area

Figure 3 shows the 3-Dimensional view of the DEM map which clearly revealed the nature of the plateau as no major peak is seen on the image. The 3-Dimensional figure revealed the same impacts of the topography on road transport development as that of the DEM map in Figure 2.

For the fact that Biu region is a plateau, the 3-Dimentional view could not really portray the actual terrain of the region to a lay man except the professionals that can use their experiences to interpret the terrain with the colour variations. Therefore, a more visual-friendly mapping called shadowing was performed and displayed in 3-dimentionsas shown in Figures 4 and 5. A closer look at the maps show the valleys, the slopes as well as the plateau tops which could be a good source of information on the terrain for transport planning and management. For instance, the road developers would have ideas on where the roads would be constructed with minimal cost by avoiding very steep as well as areas where rivers are numerous. It was also revealed from the two figures why the south western part and Kagua area in the south east are almost cut off from the rest of the plateau because of inadequate road network following the presence of wide valleys separating the two areas. The map can help road developers toassess the narrowest part of the valley where road can be constructed at minimal cost. 


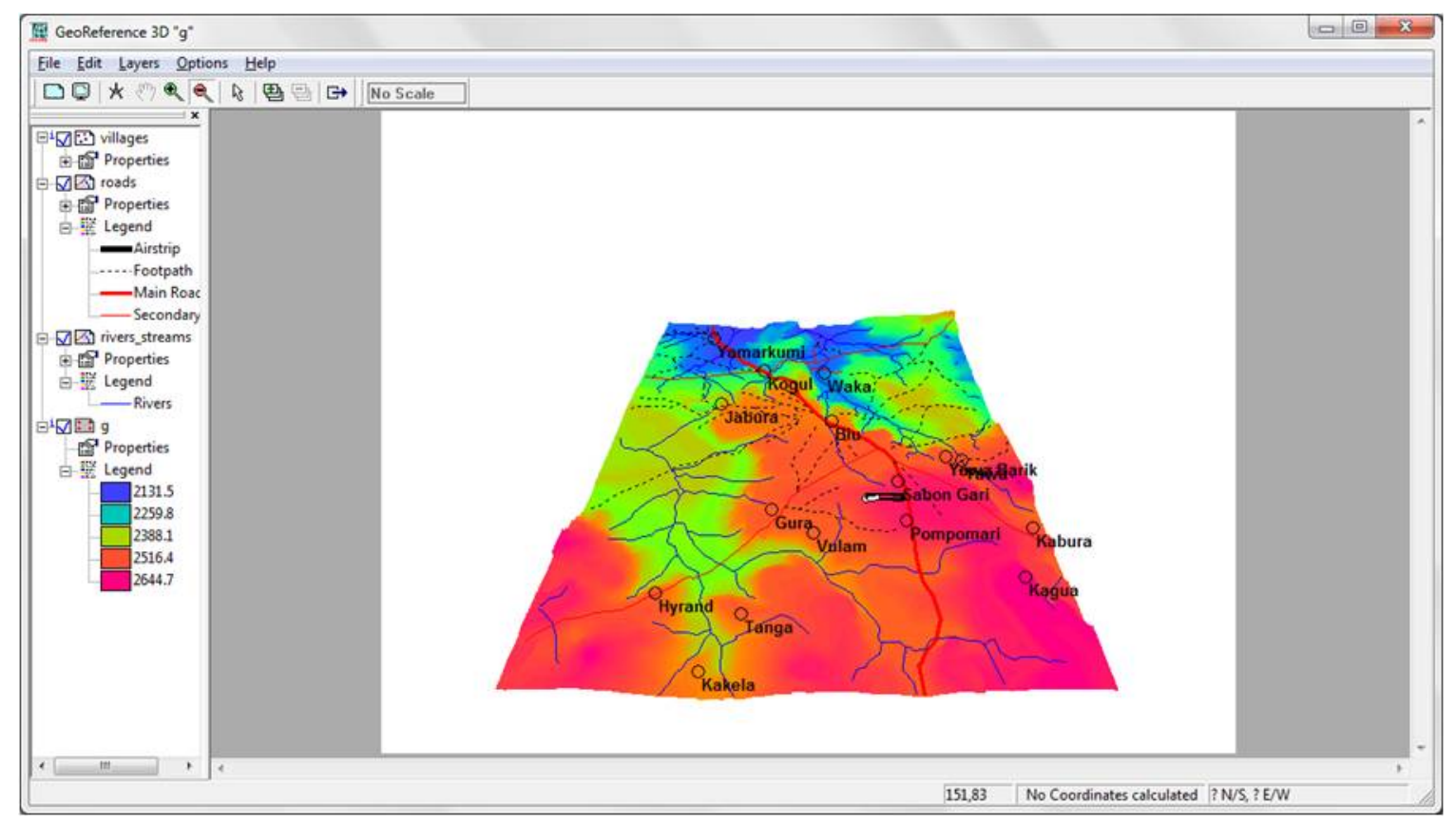

Figure 3. The 3-Dimensional view of the study area

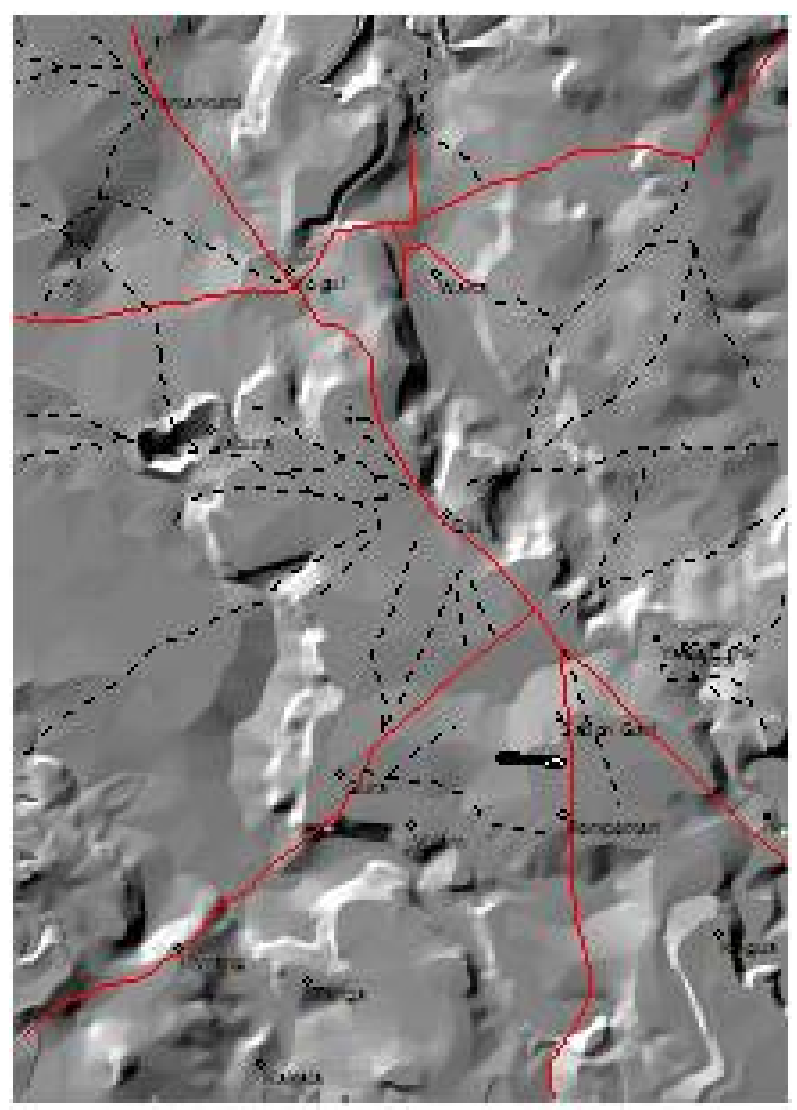

Figure 4. The shadow of the DEM

Though the slopes in Figure 5 are conspicuously visible, but the natures of the slopes are not known. Therefore the slopes were calculated as shown in Figure 6. The map clearly shows the slope in degrees ranging from $0^{\circ}$ to $35^{\circ}$. On the map, the existing roads except the roads that runs from Kagu to the eastern part and the other that links Harang in the south western part all avoid the places with high steep slopes of more than $21^{\circ}$. The slope 
map is also a good data for road planners for it can guide the planners on the route to follow during road construction and cost estimate because areas with very steep slope may attract more cost than those on plain areas. Moreover, hot spot points which may be prone to frequent accidents may also be identified on the maps. For instance the two oval shapes are the points with slopes higher than $21^{\circ}$ along the roads which may be dangerous spots because of the steep slopes. Moreover, if a road is to be constructed to link Tanga with Harang, the best route can be chosen through the inspection of the slope map (Figure 6). The lines joining the two villages are considered to be the best route because the route is located on average slope.

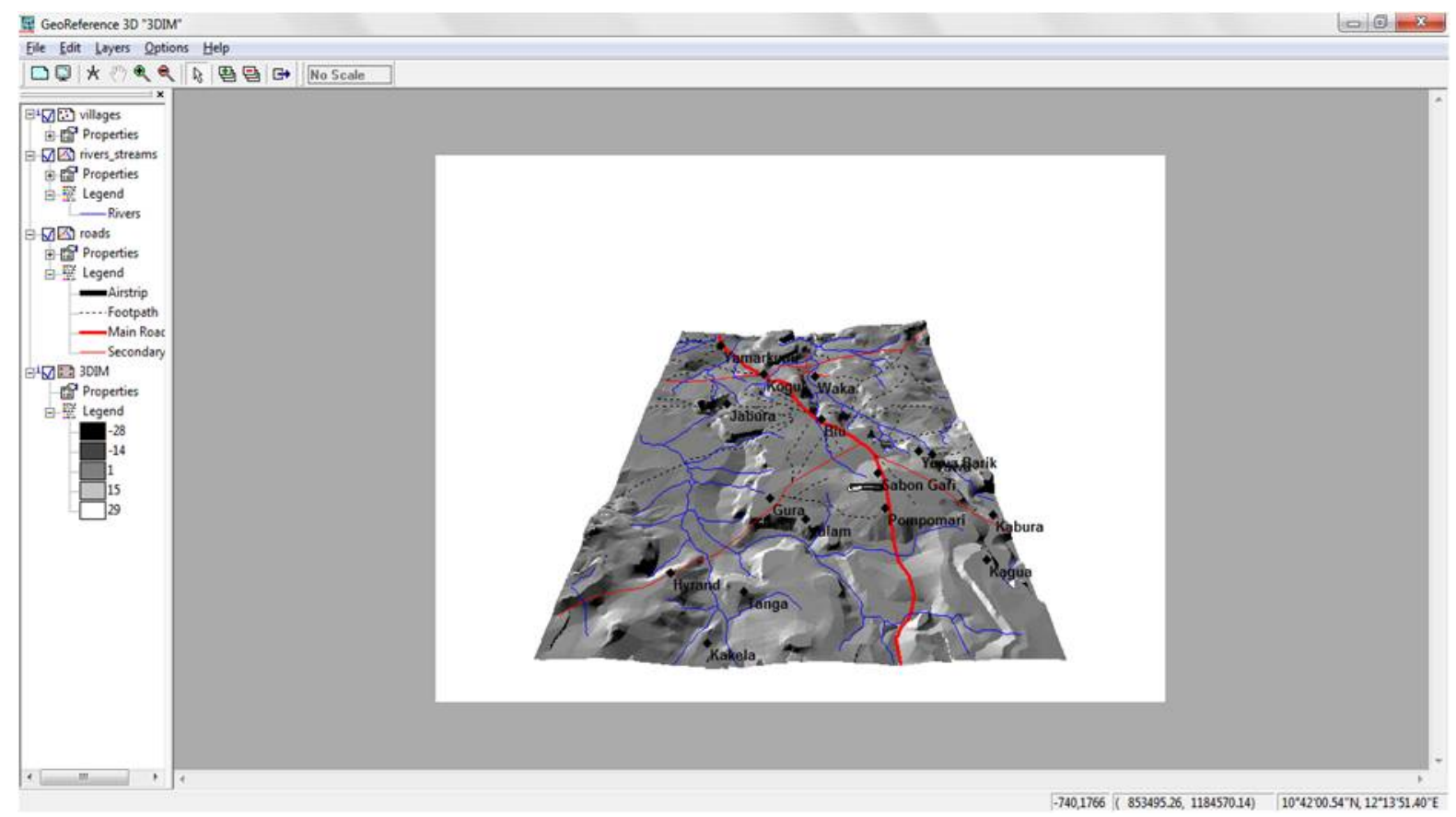

Figure 5. The 3-Dimensional view of the shadow map
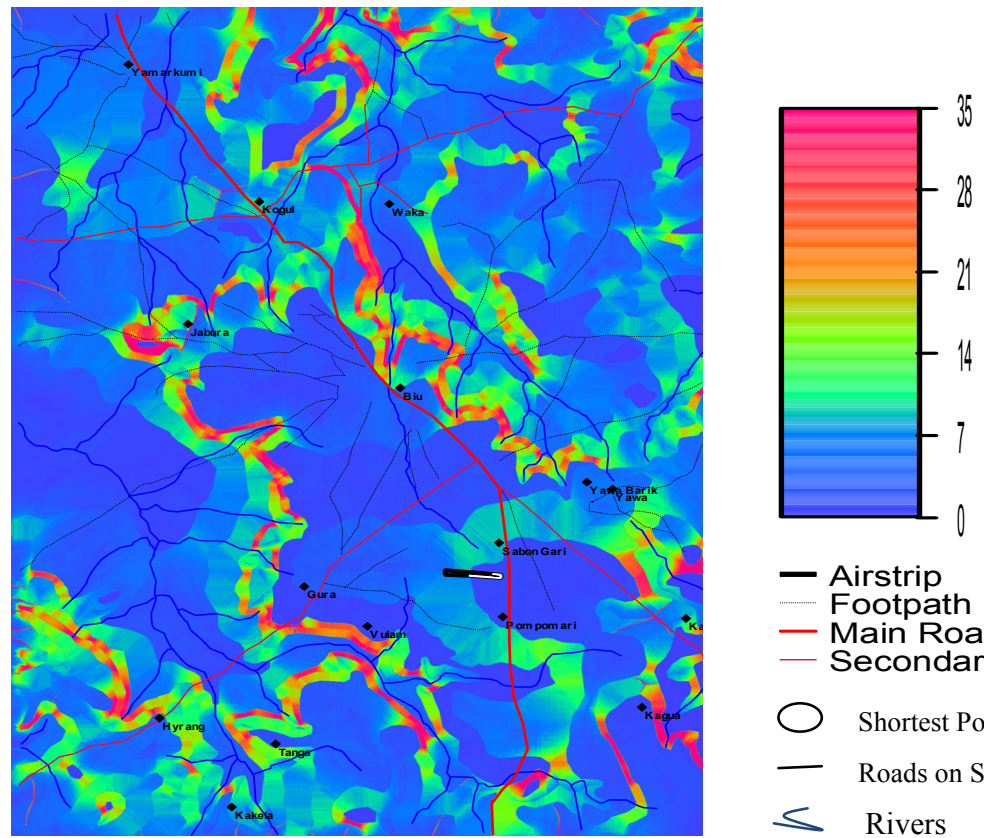

- Footpath

- Main Road

- Secondary road

Shortest Possible Road

- Roads on Sloppy Points

$\leqslant$ Rivers

Figure 6. The slope map of the area 
Finally, the direction of flow of the rivers in the area was also mapped in order to assist road planners and developers to have a good knowledge of the direction of flow of the rivers in the area which may assist them in making good decisions on construction of roads across or along such rivers. The river direction of flow map is shown in Figure 7 where red colour areas are the areas where the rivers are flown northwards, blue colour represent southwest flow directions and so on.

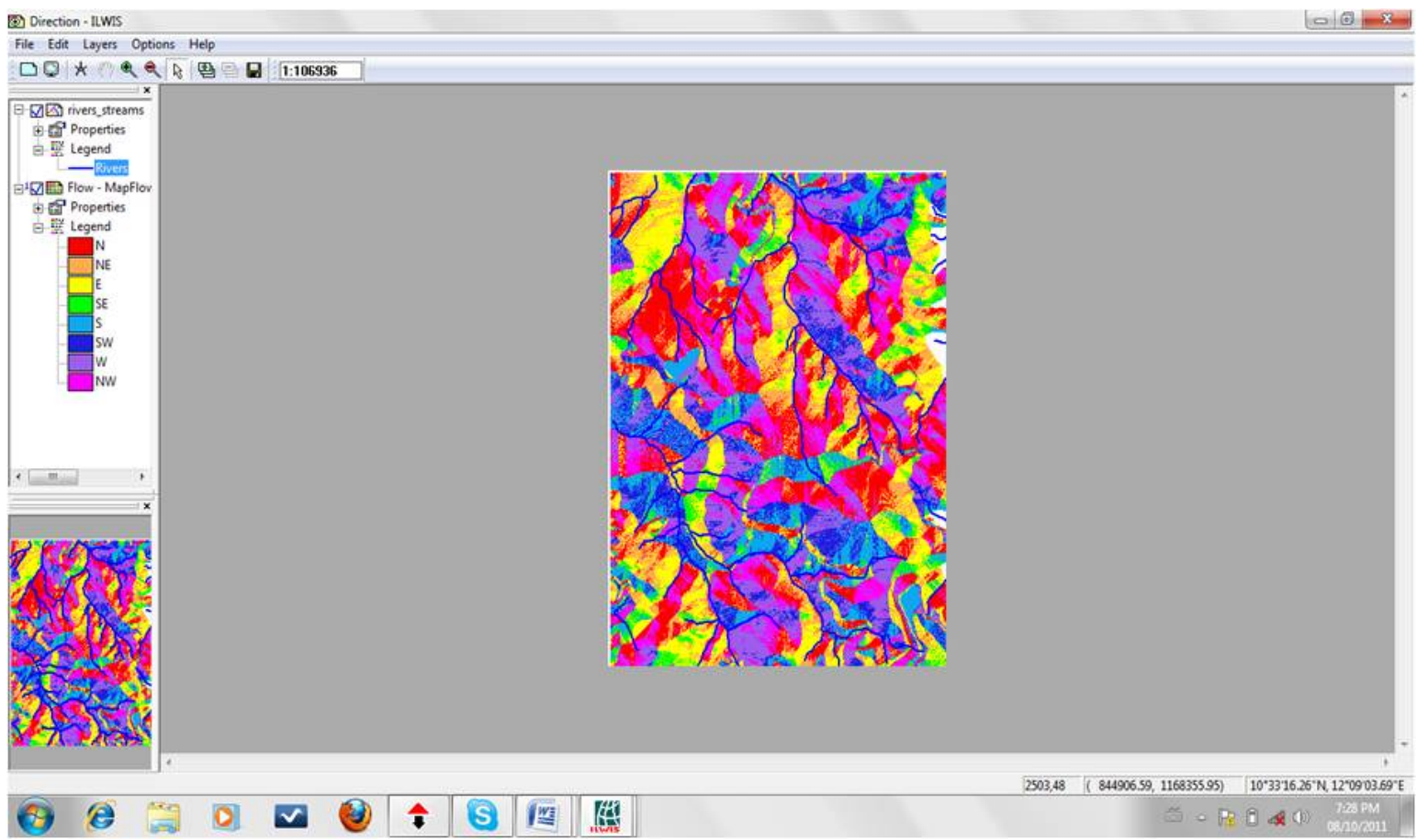

Figure 7. The direction of flow of the rivers in the area

\section{Conclusion}

The use of GIS techniques for terrain analysis has been demonstrated in this paper. Studies of the terrain to select route locations and sites for detailed geotechnical investigations are essential preliminaries to highway survey and design. The process of using all sources of information, including remote sensing to derive an understanding of the engineering characteristics of an area is known as terrain evaluation. The basis of terrain evaluation is a terrain classification, whose purpose is to act as a geographical indexing system into which all terrain-related data, collected throughout the duration of a project, may be fitted. In this paper, physical land constraints and natural hazards that affect transportation systems are explained. Interpretive maps that show the distribution of natural hazards and physical land constraints for development can be prepared from base terrain maps. These maps can be of use to planners in assessing alternative transportation corridors and in anticipating potential trouble spots before construction commences.

\section{Recommendations}

Studies of the terrain to select route locations and sites for detailed geotechnical investigations are essential preliminaries to highway survey and design.

The process of using all sources of information, including remote sensing, air photographs, and topographical maps to derive an understanding of the engineering characteristics of an area which is known as terrain evaluation cannot be overemphasized in road transportation development.

The inclusion of remote sensing data such as satellite imageries to generate transportation modelling is recommended for a real road transport planning project.

Other complex analysis which were not demonstrated in this paper but are also useful in terrain analysis such as view-shed analysis for visibility analysis and other hydro-processing analysis are encouraged to be performed especially in real road engineering work. 
Furthermore, the principles of interpolation and visualization and digital terrain models may be applied to other types of three dimensional data to generate geophysical measurements.

All the stake holders in road transportation planning and development are hereby encouraged to have a deep knowledge of GIS technique for terrain analysis as a lot of time, money and energy are saved with high accuracy and reliability of output maps, provided the necessary data are available.

\section{References}

Church, R. J. (1979). A new outline Geography of West Africa. London: Harrap.

Iloeje, N. P. (2007). A New Geography of Nigeria (5th ed.). Nigeria: Longman Press, Ibadan.

Linda, M. (2003). Digital Topographical Support System-Terrain Analysis. U. S. Army Topographic Engineering Centre. Retrieved from www.tec.army.smil.mil

Muhammed, A. J., \& Muhammad, W. (2009). Rural Transport in Kala Balge Local Government Area (Vol. 1). In Issues in the Geography of Borno State, AdamuJoji Publishers, Kano.

Ndukwe, N. K. (2001). Digital Technology as Surveying and Mapping: Principles, Applications and Legislative Issues. India: PhyleKerex Publishers Ltd, New Delhi.

Udo, R. K. (1978). A comprehensive geography of West Africa. Heinemann educational books.

Wali, U., \& Dabo, A. A. (2009). Study of the Effects of Slope in the Incidence of Road Traffic Accidents. A Case Study of Bauchi-Yola road in Gombe. Journal of Environmental Sciences, 13.

\section{Copyrights}

Copyright for this article is retained by the author(s), with first publication rights granted to the journal.

This is an open-access article distributed under the terms and conditions of the Creative Commons Attribution license (http://creativecommons.org/licenses/by/3.0/). 